\title{
GEOMETRY OPTIMIZATION BY FEM SIMULATION OF THE AUTOMATIC CHANGING GEAR
}

\author{
Ana Pavlovic ${ }^{1}$, Cristiano Fragassa ${ }^{1}$ \\ ${ }^{1}$ Department of Industrial Engineering, University of Bologna, Bologna, Italy \\ e-mail: ana.pavlovic@unibo.it \\ e-mail: cristiano.fragassa@unibo.it
}

\begin{tabular}{l} 
Article Info \\
\hline Article history: \\
Received November 6, 2020 \\
Revised December 22, 2020 \\
Accepted December 30, 2020 \\
\hline
\end{tabular}

\section{Keywords:}

FEM Simulation, Accelerated life test, Process Control.

\begin{abstract}
Electro-mechanic devices for the automatic changing of gear were tested by company using the same accelerated life testing procedures in different stages of the product development. All the tested prototypes satisfied the experimental conditions for accelerated life tests, while 50\% of components coming from the first sample of serial production showed crack phenomena during the same testing procedure. This situation can be related to a large number of undefined factors: from the variability of material proprieties or in production process parameters to accidentally different conditions in testing. The complete list of all the possibilities of variance was extremely complex to be defined, recognized and verified by new sets of experimental tests. FEM calculation permitted a fast simulation of the component response under the complex experimental testing conditions, modifying the interpretation of some experimental results and correctly driving the designer toward quick improvements of product.
\end{abstract}

Copyright (C) 2020 Regional Association for Security and crisis management and European centre for operational research. All rights reserved.

\section{Corresponding Author:}

Ana Pavlovic,

Department of Industrial Engineering, University of Bologna.

E-mail: ana.pavlovic@unibo.it

\section{Introduction}

Proposed component is a widespread electro-mechanic device for the automatic shifting of gear, so called sele-speed, realized by Marelli and fitted up the worldwide high-class motorcars of different companies. This system belongs to a complex line of products that needs a continuous R\&D action for further function developments and quality improvements. A fundamental task in the quality assurance activity is related to the reliability evaluation of component before delivering, performed using an accelerated life testing procedures. The same accelerated life testing procedure was used to be performed in different stages of the product development: from first prototypes to the ultimate components of the stable production chain.

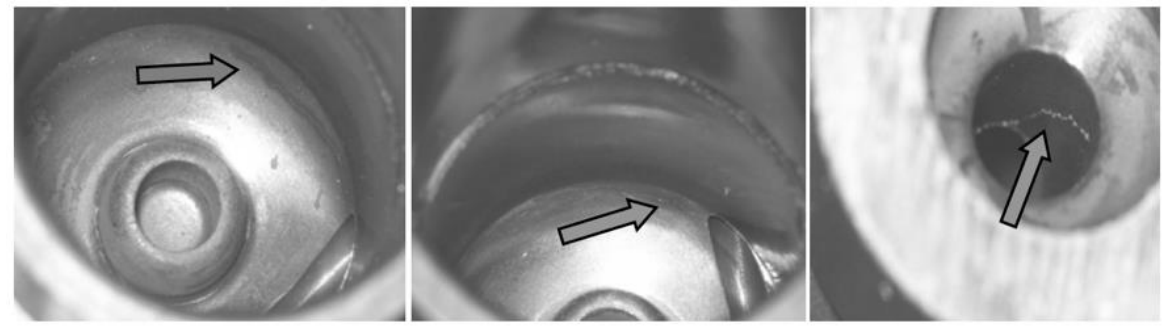

Figure 1. Damaged area 
All the tested prototypes satisfied the experimental conditions for accelerated life tests, while $50 \%$ of components coming from the first sample of serial production showed crack phenomena during the same testing procedure Figure, 1. This situation (of tests satisfied on prototypes and not satisfied on production) can be related to a large number of undefined factors: from the variability of material proprieties or in production process parameters to accidentally different conditions in testing. The complete list of all these possibilities of variance was extremely complex to be defined, recognized and verified by new set of experimental tests since each life test needed about 60 days to be planned, completed and analysed while the production had to be delivered in less than 3 months.

The Finite Element Method (FEM) is addressed here as currently the most power numerical tool for structural analysis (Bathe, 2014). It enables various types of structural analysis including linear and nonlinear (Marinkovic \& Zehn, 2019), static and dynamic analysis (Zhang et al, 2020), modal analysis (Tigh Kuchak et al, 2020), stability analysis (Wierzbicki et al, 2020), thermal analysis (Miltenović \& Banić 2020), coupled field problems (Rama et al, 2018), etc. The versatility of the method allows for all types and combinations of kinematic and dynamic boundary conditions. It is also often used with the aim of optimizing structural geometry. The FEM analysis provides a detailed stress state in the structure, so that a reasonable choices can be made in which structural areas material can be removed or should be added. Over a number of such iterations, the structural geometry can be significantly improved (Wang \& Wang, 2004; Karban et al. 2021).

FEM calculation, performed using ANSYS Workbench 19.2 (Lee, 2018), permitted a fast simulation of the component response under the complex experimental testing conditions and further specific boundary conditions, suitable to demonstrate the validity of some theoretical hypotheses. FEM simulation showed the limits of the adopted experimental procedures, changing the interpretation of previous results, supporting the implementation of new quick experimental tests and driving the designers toward the fast improvements of correct solutions.

\section{Experimental Condition}

Components were tested using a thermo-mechanically stress condition, in a pulsed way, by a pressure impulse and a thermal cycle. The pressure complex curves in Figure 2, performed by an external air compressor, and were used to simulate a like-real alternation of fast loads. From the Figure 2, it is possible to distinguish that for a pressure of $\mathrm{p}=35 \mathrm{bar}$, max displacement is $\mathrm{x} \approx 0.16 \mathrm{~mm}$ with an inertial response of the material.

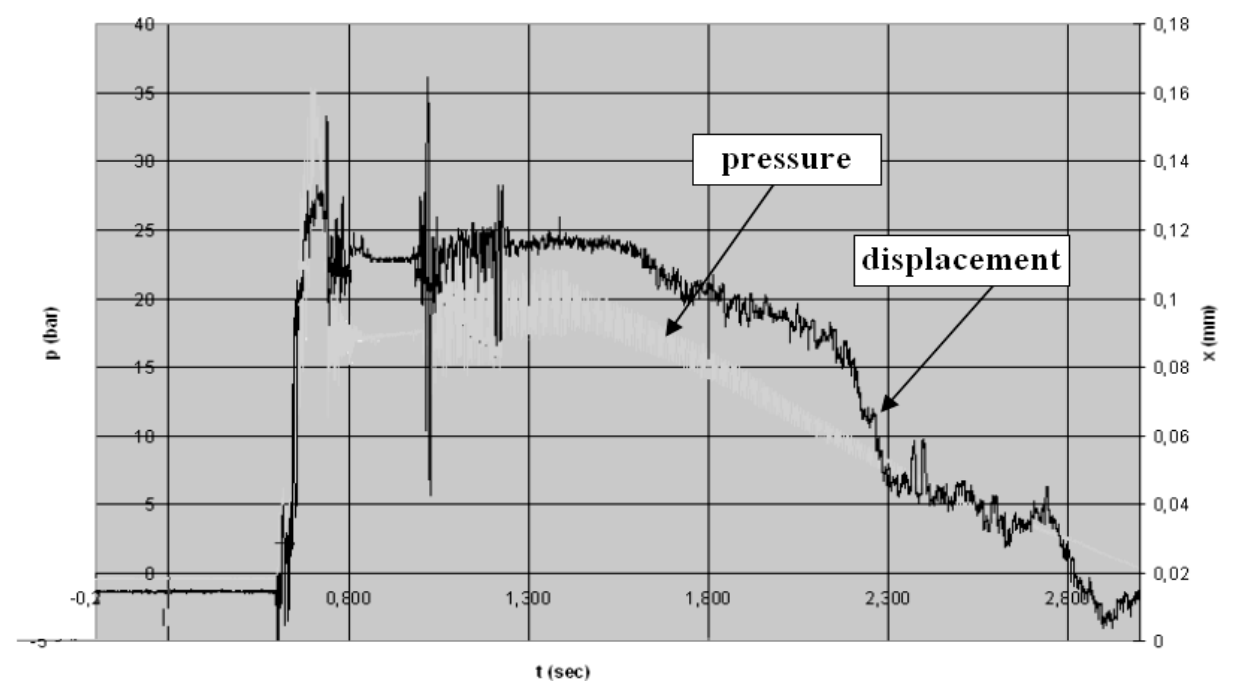

Figure 2. Diagram of experimental conditions

Thermal variations, performed by an experimental oven, were utilized to represent the environmental modifications in engine proximity. Global experimental conditions were:

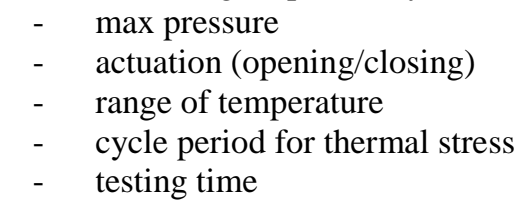

$35 \mathrm{bar}$

1 cycle every $4 \mathrm{~s}$

$-30^{\circ} \mathrm{C}$ to $120^{\circ} \mathrm{C}$

$24 \mathrm{~h}$

2.000.000 cycle of pressure (about 3 months) 

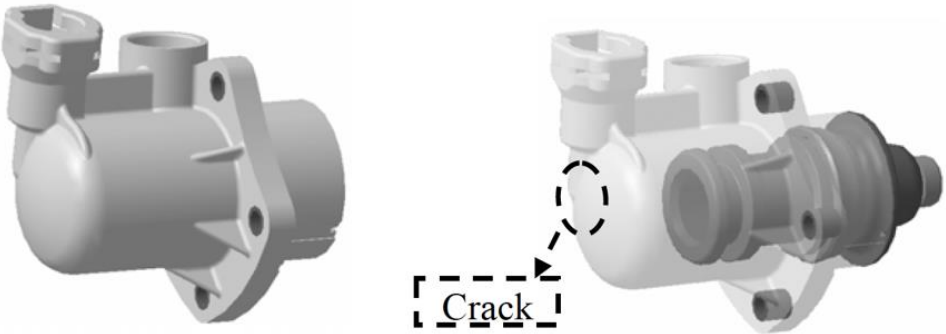

Figure 3. Cracked part of automatic changing gear

All the 4 tested prototypes satisfied the experimental conditions arriving to two millions of cycles without any defect, while 2 of 4 tested components, coming from the serial production, had a significant loss of oil since 800.000-1.000.000 of cycles; the other 2 components were under testing but with lower number of cycles. After an accurate observation, the problem was limited to a part of the component, the final connector, with the crack apparently starting from the point of geometric intersection between the line of changing of shape convexity and the edge of a little hole as in Figure 3. So the problem could be interpreted like a mistake in design that created a point for stress concentration and crack genesis, but, in this case, it was not clear for which reason all prototype survived while all components cracked at $50 \%$ of the aging degree. A large number of hypotheses were proposed but it was not possible to check them by new experimental tests.

\section{Finite Element Numerical Simulation}

FEM simulation offers sets of results that contain very important information for present-day engineering, like a complete map of stresses and deformations condition. In this case, essence was to inquire and analysed part of automatic changing gear, by FEM numerical method, creating a large number of cases studies with extreme, but like-real, conditions and showing in which way loads and boundaries influence the system.

\subsection{Boundary conditions}

Although the load influence (pressure and temperature) were simple to model, for the boundary conditions it was necessary to try different combinations. The part is fixed to the structure by 4 holes with screws on the base and 2 tubes on the lateral surface as in Figure 4a. The selected boundary conditions had to correctly take in count either of material expansion or system working situations, since the maximum stress value and displacement, are strongly related to the kind of boundary conditions. For example, fixed constrains on holes could not appropriately represent the freedom of extending material to fill up the under millimetric gaps between screws and surfaced increasing the simulated level of stress and displacement more than in the reality. At the same time, one of the external tubes, under the working pressure of 35 bar, could force the part with an additional impulsive shear load and with a compulsion ring force on connection. Different boundary conditions ("case study") were calculated and a comparison between measured and simulated displacement permitted to choose the right combination of constrains. In this case study (case 6 and 8), where there was a smaller difference of displacement in the area of crack between simulation and experiment results, the boundary conditions were chosen to permit to the material a partial free expansion along the transversal direction with a constrains system of:

1. no movement allowed in $\mathrm{X}$ and $\mathrm{Y}$ directions for two opposite hole-zone;

2. no movement allowed in $\mathrm{Z}$ and $\mathrm{Y}$ directions for the other hole-zone;

3. upper tube completely free (case 6) or totally fixed (case 8) with a rigid constrain.

a)

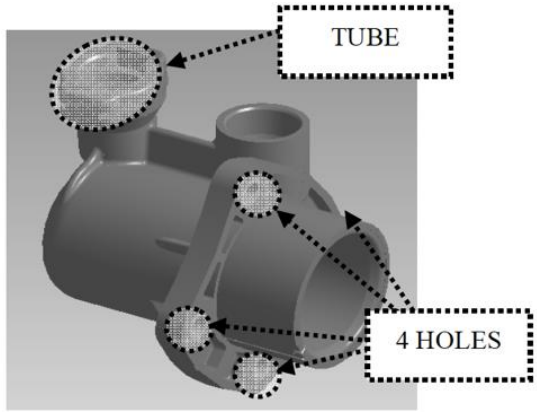

b)

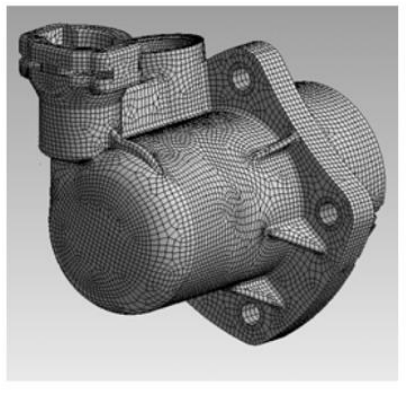

Figure 4: a) Boundary conditions; b) finite element mesh of the model

Geometry optimization by fem simulation of the automatic changing gear (Ana Pavlovic) 


\subsection{Material Properties}

The part is realized in a semi-crystalline resins based on the polymer designated AMODEL A-1000 polyphthalamide. These resins have excellent mechanical properties, outstanding dimensional stability, exceptional elevated thermal performance, and good processing characteristics. According to (Ponticel, 2002; Solvay et al, 2004) it was possible to conclude that AMODEL 1145 HS BK 324 is an anisotropic resin with thermal expansion coefficient of $1.5 \times 10-5 \mathrm{C}-1$, Young's modulus of $17200 \mathrm{MPa}$, Poisson's ratio of 0.41 and ultimate stress of _about $60 \mathrm{MPa}$. For fatigue loads, the strength was evaluated of $\sigma \mathrm{max}=27.3 \mathrm{MPa}$ for $\mathrm{T}=120^{\circ} \mathrm{C}$ and $2 \times 106$ cycles.

\subsection{Other conditions for simulation}

The default mesh of "All Tetrahedrons" with size of $1.5 \mathrm{~mm}$ and $1 \mathrm{~mm}$ didn't give a good approximation of the model (Bathe, 2014; Slavkovic, 1994). A "HEX Dominant" (Prism) mesh, with 146706 nodes, 48710 elements of $1.5 \mathrm{~mm}$, offered better results with a smaller grid and better connection between elements in the areas of interests, Figure $4 \mathrm{~b}$.

\section{Discussion and Conclusion}

FE static method, performed by ANSYS Workbench 19.2, permitted to evaluate stresses and displacements values. In particular it was possible to numerically verify that:

- the calculated displacements were pretty comparable with the experimental values (up to $0.12 \mathrm{~mm}$ )

- better results could be obtained only taking in count of the dynamic forces and impulses;

- the temperature did not change the stress distribution in the area of crack where the part is practically free to expand (Table 1 case 5-9);

- the anisotropic thermal characteristic of material (up to 4 times for the thermal expansion coefficients in the orthogonal directions) did not largely influence the condition of starting of cracks;

- the influence of tube rigidity on the area of crack is limited to $20 \%$, but in the opposite way respected to the initial hypothesis: increasing the level of boundary decreases the stress value of crack zone since the new rigid constrain reduces the influence of temperature displacements (case 8 and 10);

- the maximum level of stress exactly appeared in the same area where the cracks experimentally came out (except for some particular but not interesting situations close to the boundary zones);

- no other zone is at a considerably high level of stress to be noticed for redesign (Figure 5, Figure 6);

- the maximum stress value is equivalent to the ultimate stress and twice higher than the fatigue limit.

Table 1. Review of results (case 1-4 used to define the right boundary conditions)

\begin{tabular}{|c|c|c|c|c|c|c|}
\hline \multirow[t]{2}{*}{ Solution } & $\begin{array}{l}\text { Case } \\
\text { study }\end{array}$ & $\mathbf{T}$ & $\mathbf{P}$ & Stress & $\begin{array}{l}\text { Boundary } \\
\text { conditions }\end{array}$ & \multirow[t]{2}{*}{ Remarks } \\
\hline & $\mathrm{N}^{\circ}$ & {$\left[{ }^{\circ} \mathrm{C}\right]$} & [bar] & [MPa] & on tube & \\
\hline \multirow{6}{*}{$\begin{array}{l}\text { Original } \\
\text { solution }\end{array}$} & 5 & - & 35 & 70 & free & only pressure \\
\hline & 6 & 120 & 35 & 70 & free & adding T; same stress [5] \\
\hline & 7 & - & 35 & 67 & fixed & only pressure; similar stress $[5,6]$ \\
\hline & 8 & 120 & 35 & 60 & fixed & fixed tube; reduce of stress [6] \\
\hline & 9 & 120 & - & 0 & fixed & only temperature; no stress \\
\hline & 10 & 120 & 35 & 60 & forced & tube forced to move; same stress [8] \\
\hline \multirow{2}{*}{$\begin{array}{l}+1.5 \mathrm{~mm} \text { of } \\
\text { material }\end{array}$} & A6 & 120 & 35 & 55 & free & \multirow{2}{*}{$\begin{array}{l}\text { solution A decrease stress }[6,8] \text { of } 30- \\
40 \%\end{array}$} \\
\hline & A8 & 120 & 35 & 44 & fixed & \\
\hline \multirow{2}{*}{$\begin{array}{l}\text { changing of } \\
\text { curve }\end{array}$} & B6 & 120 & 35 & 30 & free & \multirow{2}{*}{$\begin{array}{l}\text { solution B decrease stress }[6,8] \text { of } 30- \\
40 \%\end{array}$} \\
\hline & B8 & 120 & 35 & 21 & fixed & \\
\hline \multirow{2}{*}{$\begin{array}{l}\text { local } \\
\text { reinforcements }\end{array}$} & C6 & 120 & 35 & 40 & free & \multirow{2}{*}{$\begin{array}{l}\text { solution } \mathrm{C} \text { decrease stress }[6,8] \text { of } 40 \text { - } \\
50 \% \text { (without changing the shape) }\end{array}$} \\
\hline & C8 & 120 & 35 & 35 & fixed & \\
\hline
\end{tabular}


Next step was to create fast redesigning solutions by which avoid the crack growth and propagation. The software tool CATIA V5-6R2013 (Cozzens, 2013) was used to redesign the new solid models that, by the same FEM simulation, were analysed and compared in the same conditions of boundaries and loads. Every improvement of design could be accepted only without provoking new significant costs in the product (no changing allowed in the position of external connections) or in the process (no changing of the mould).
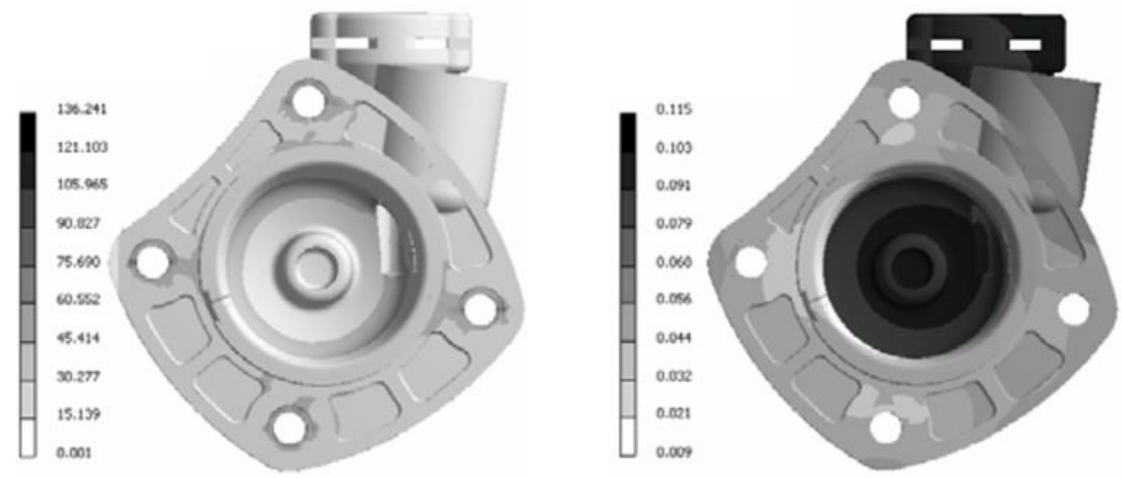

Figure 5: Stress and displacement distributions; case 6, tube free
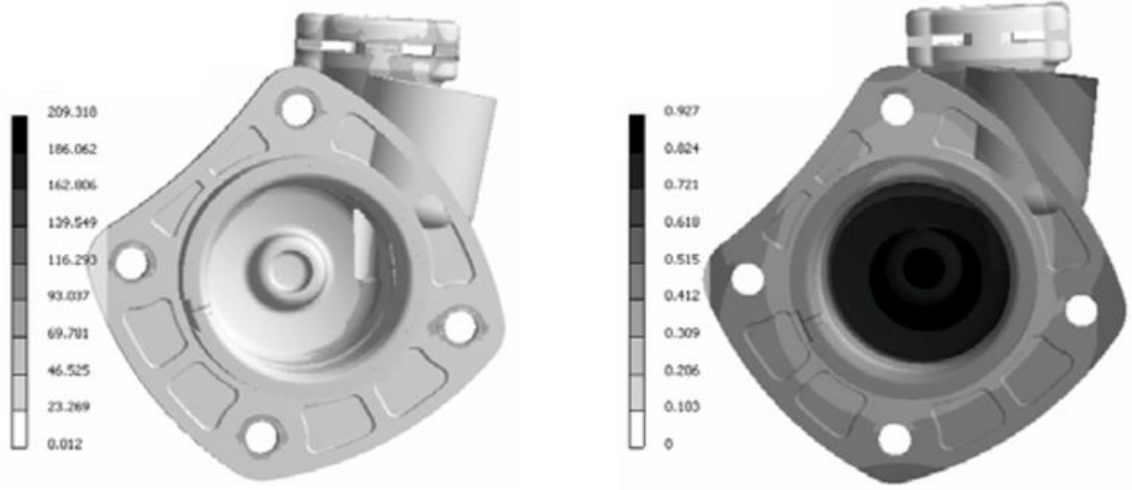

Figure 6: Stress and displacement distributions; case 8, tube fixed

The first modification, case A, was obtained adding a little portion of material $(1.5 \mathrm{~mm})$ on the back part of the model, close to the crack zone. The second solution, case B, that gives the best results, was obtained by the combination of first adding of material with a different fillet radius of $1 \mathrm{~mm}$ in critical area, Figure 7 . With these small changes, the respect of costs were guaranteed. After the examination of all results, a third solution, case $\mathrm{C}$, was adopted since its simple way to renew the old process. The new model has addition reinforcements for more rigidity, printed in the inner part, Figure 8.
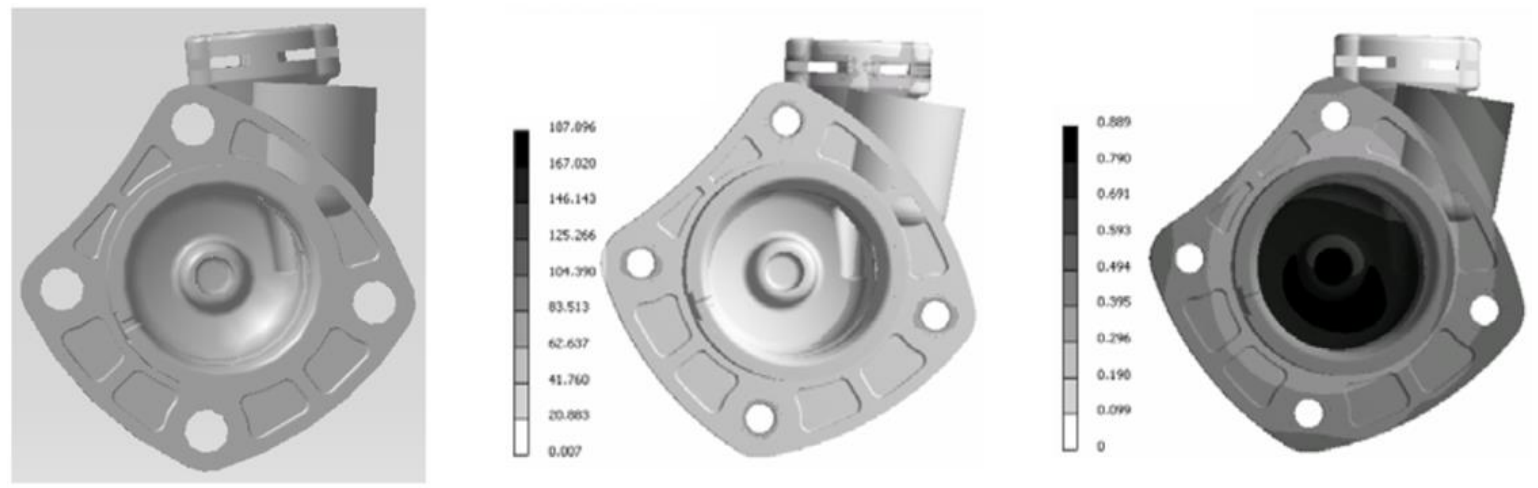

Figure 7: New model with adding material and different fillet radius (case B) 

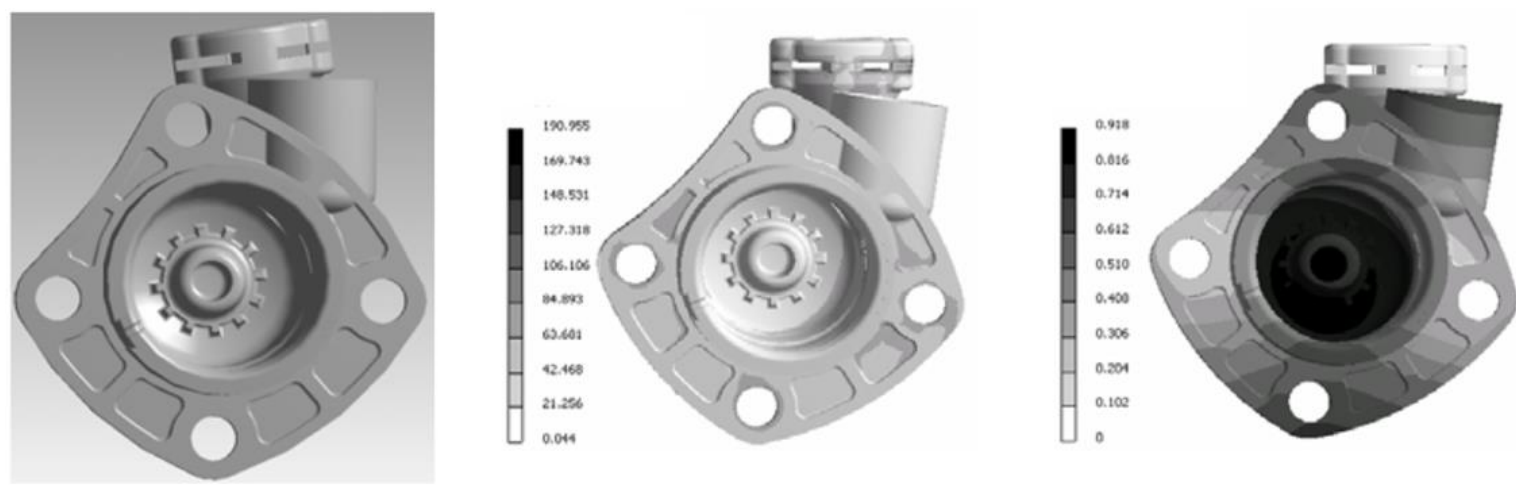

Figure 8: New model with reinforcements for more rigidity (case C)

Introducing FEM methodology during the experimental activity, it was possible to obtained different practical advantages in a very easy way. It was clarify, for example, that:

○ the temperature was not influent for crack growth, simplifying further experimental tests;

○ the anisotropic behaviour of material was not important for crack problems;

- mechanic loads significantly outrun the elastic limit, but not the ultimate stress demonstrating crack growth was a fatigue problem, related to errors in design and not in process;

- all the exploding tests, proposed by the company to reduce the testing time, were useless and, in any case, it is necessary to move toward pulsed tests able to simulate the mechanical damage and aging;

- after corrected the geometry of that particular area, no other zone appeared to be critic, and at the same time, if a crack grow up, then it started from that point;

$\circ \quad$ the rigidity of the tubes are not influent on crack problems and, related to this, it is not necessary to pay attention, as supposed, to the strict respect of some particular geometric dimensions;

- little geometric imprecision and movements during mounting in experiments could not be the reason of crack arising, and, more generally, the tests were not so sensible to the experimental conditions.

FEM simulation techniques can be extremely useful to direct and to interpret experimental tests saving resources and reducing the risk of mistakes in diagnosis. Unexpected experimental results, turned up during delivering tests performed by an international manufacturer of equipment for car industry, gave the motivation for this study. Using FEM simulation to clear out experimental results and other kind of information (like, for instance, material propriety under thermal-mechanic cycled stress) it was possible to realize shorter testing procedures and to direct the design team toward a robust re-design of the assembly. Moreover, by the description of an important, commercial, case study, the aim of this paper was to demonstrate how experimental results, if not supported by simulations, could easily carry away the observers toward wrong conclusions. Theoretical models, computer simulations and experimental techniques are essential tools of the same path toward the correct knowledge of phenomena: without one of these aspects the comprehension of the reality could be incomplete or, even, incorrect.

\section{References}

Bathe, K. J. (2014). Frontiers in finite element procedures \& applications. In: Computational Methods for Engineering Science, (BHV Topping, ed.), Saxe-Coburg Publications, Stirlingshire, Scotland.

Cozzens, R. (2013). CATIA V5 Workbook Release V5-6R2013. Sdc Publications.

Tigh Kuchak, A.J., Marinkovic, D., \& Zehn, M. (2020). Finite element model updating - Case study of a rail damper. Structural Engineering and Mechanics, 73(1), 27-35.

Karban, P., Pánek, D., Orosz, T., Petrášová, I., \& Doležel, I. (2021). FEM based robust design optimization with Agros and Ārtap. Computers and Mathematics with Applications, 81, 618-633.

Lee, H. H. (2018). Finite element simulations with ANSYS Workbench 18. SDC publications.

Marinkovic, D., \& Zehn, M. (2019). Survey of finite element method-based real-time simulations. Applied Sciences, 9(14), 2775.

Miltenović, A., \& Banić, M. (2020). Thermal analysis of a crossed helical gearbox using FEM. Transactions of Famena, 44(1), 67-78. 
Ponticel, P. (2002). Solvay AMODEL PPA for thermostat housing. Automotive Engineering International (USA), 110(6), 64.

Rama, G., Marinković, D., \& Zehn, M. (2018). Efficient three-node finite shell element for linear and geometrically nonlinear analyses of piezoelectric laminated structures. Journal of Intelligent Material Systems and Structures, 29 (3), 345-357.

Slavković, R., Živković, M., \& Kojić, M. (1994). Enhanced 8-node three-dimensional solid and 4-node shell elements with incompatible generalized displacements. Communications in Numerical Methods in Engineering, 10(9), 699-709.

Solvay, S. A., \& Amodel, P. P. A. (2004). PPA improves fuel pick-up tube's performance. Reinforced Plastics, 48(5), doi: 10.1016/S0034-3617(04)00288-7.

Wang, S. \& Wang, M.Y. (2006). A moving superimposed finite element method for structural topology optimization. International Journal for Numerical Methods in Engineering, 65(11), 1892-1922.

Wierzbicki, K., Szewczyk, P., Paczkowski, W., Wróblewski, T., \& Skibicki, S. (2020). Torsional stability assessment of columns using photometry and FEM. Buildings, 10(9), 162.

Zhang, B., Li, H., Kong, L., Shen, H., \& Zhang, X. (2020). Size-dependent static and dynamic analysis of Reddy-type micro-beams by strain gradient differential quadrature finite element method. Thin-Walled Structures, 148, 106496. 